\title{
Alternating Diacetylene Copolymer Utilizing Perfluorophenyl-Phenyl Interactions
}

\author{
Rui Xu, Volker Gramlich, Holger Frauenrath* \\ Eidgenössische Technische Hochschule Zürich, Department of Materials, Hönggerberg, \\ HCI H515, CH-8093 Zürich, Switzerland \\ Email: frauenrath@mat.ethz.ch
}

\section{Supporting Information}

\section{Table of Contents}

NMR Spectra of Compounds 4-12

Raman Spectra of Compound 6 


\section{${ }^{1} \mathrm{H}$ NMR spectrum of $\mathbf{4}$}

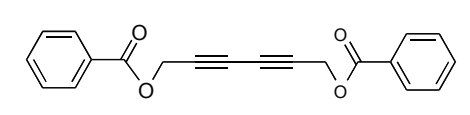

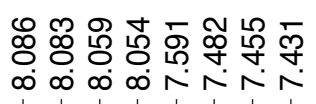
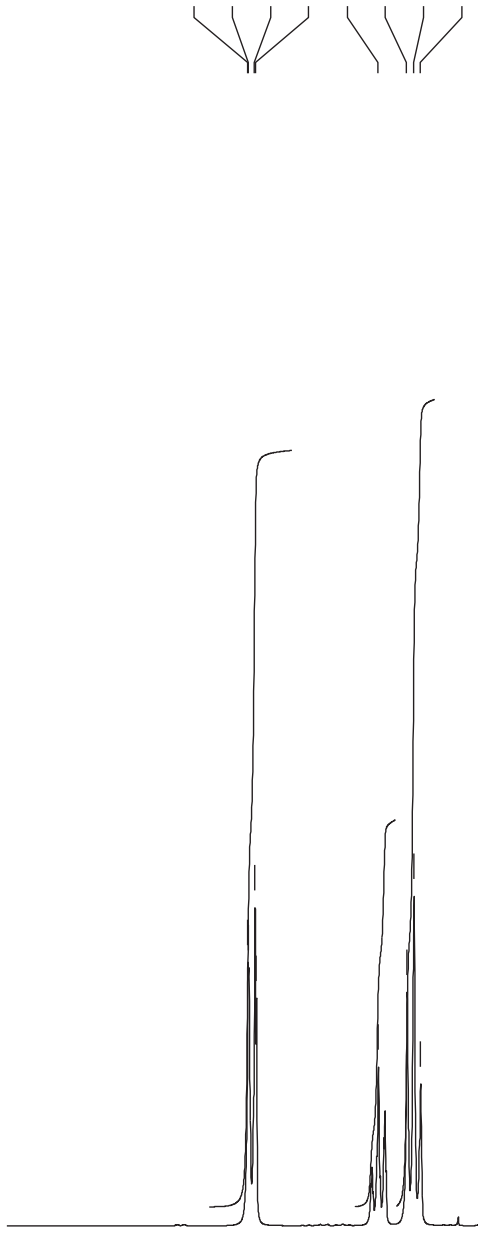

8.5

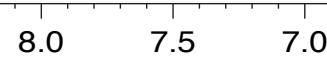

6.5

6.0

5.5

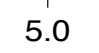

4.5

3.5

3.0

2.5

2.0

1.5 ํำ 


\section{${ }^{13} \mathrm{C}$ NMR spectrum of 4}
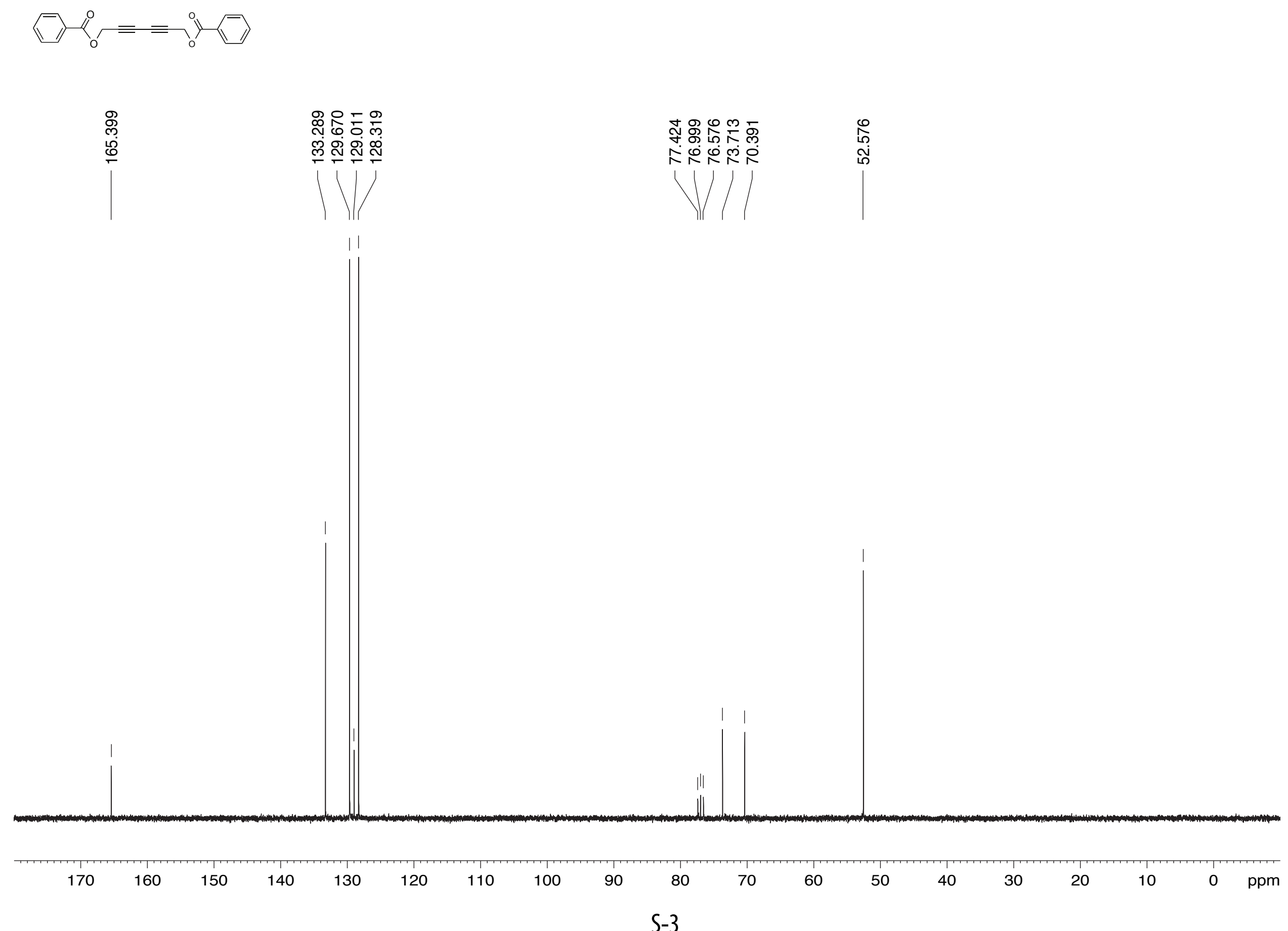


\section{${ }^{1} \mathrm{H}$ NMR spectrum of $\mathbf{5}$}
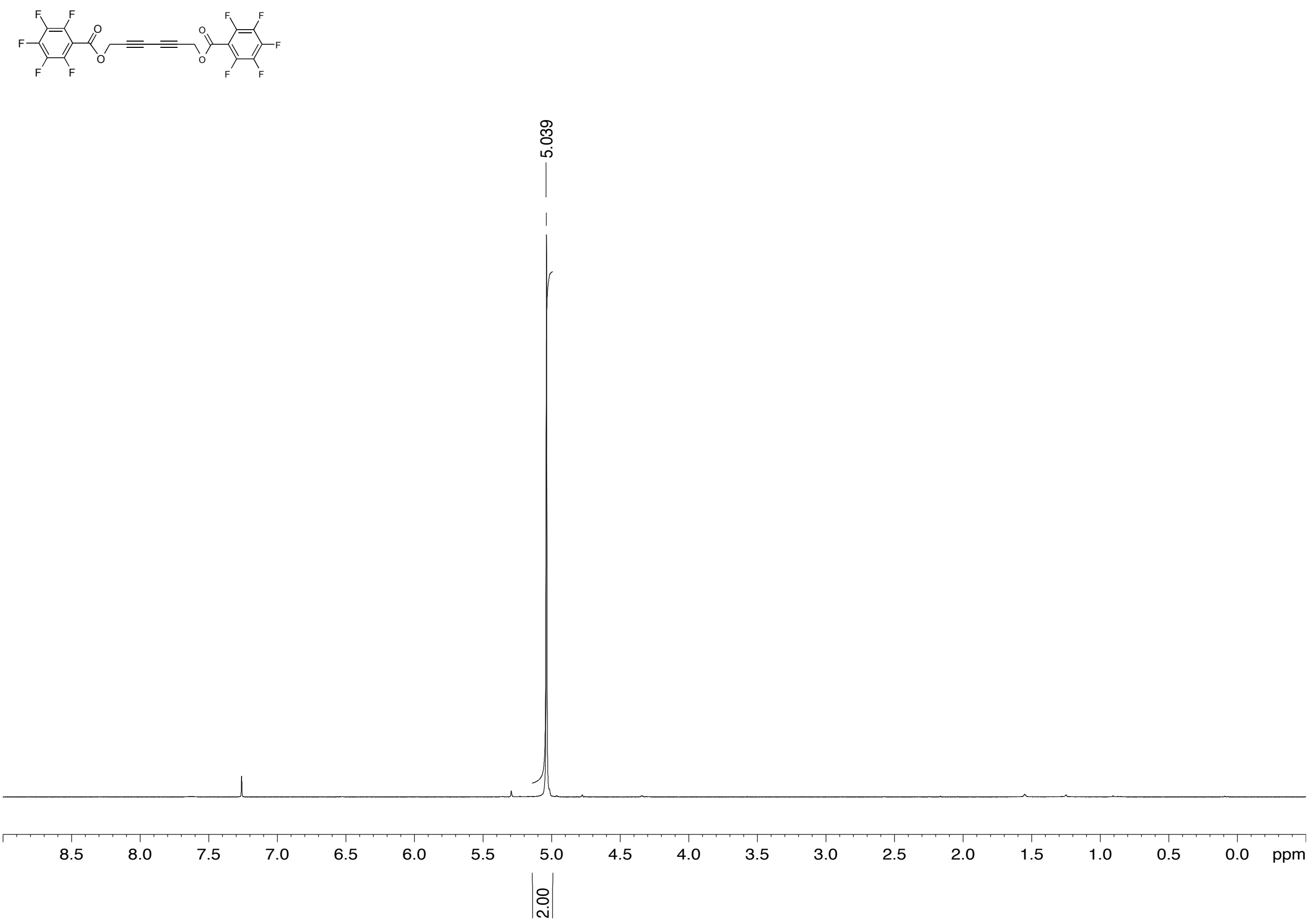
${ }^{19} \mathrm{~F}$ NMR spectrum of $\mathbf{5}$
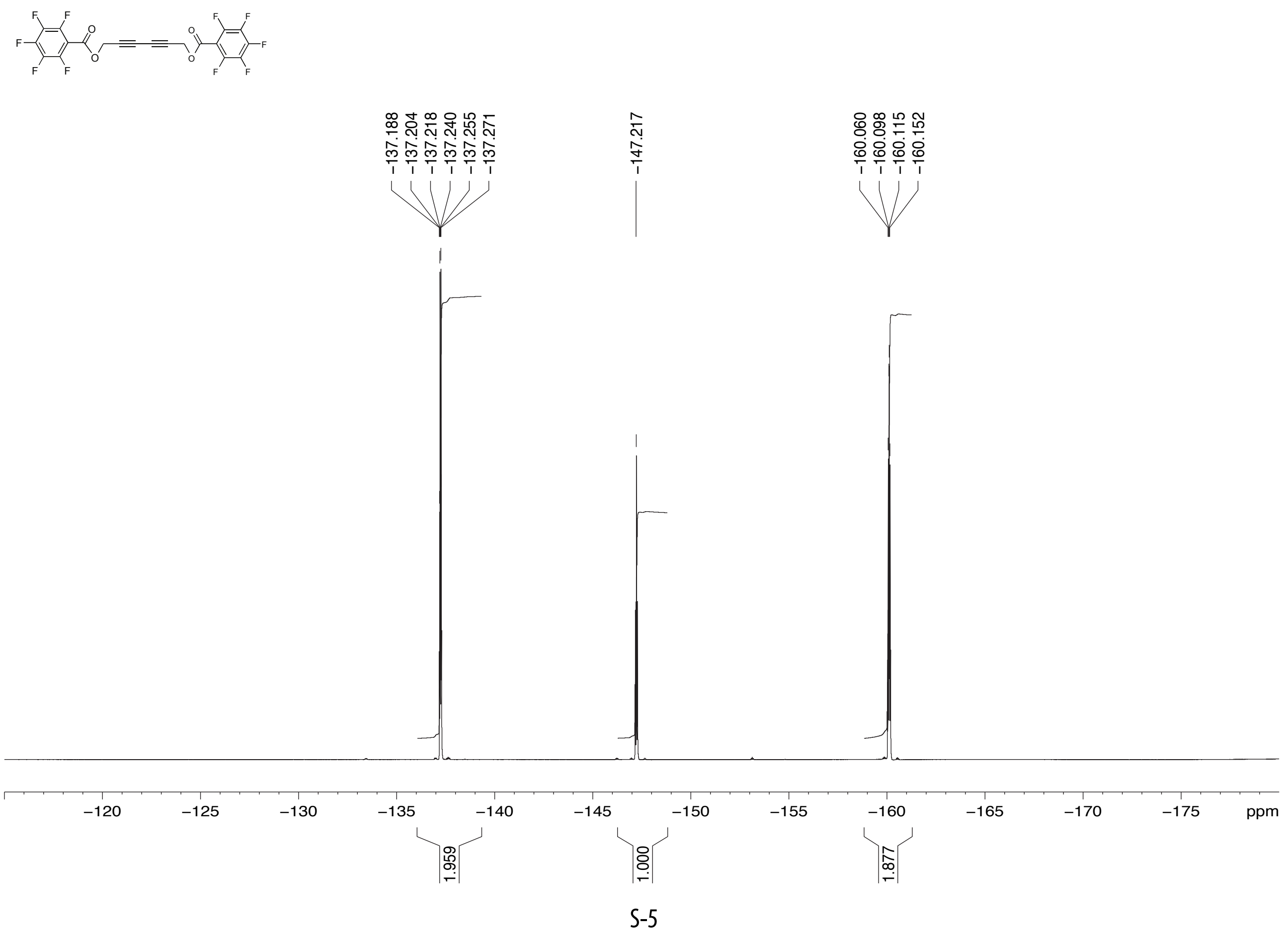
${ }^{13} \mathrm{C}$ NMR spectrum of $\mathbf{5}$
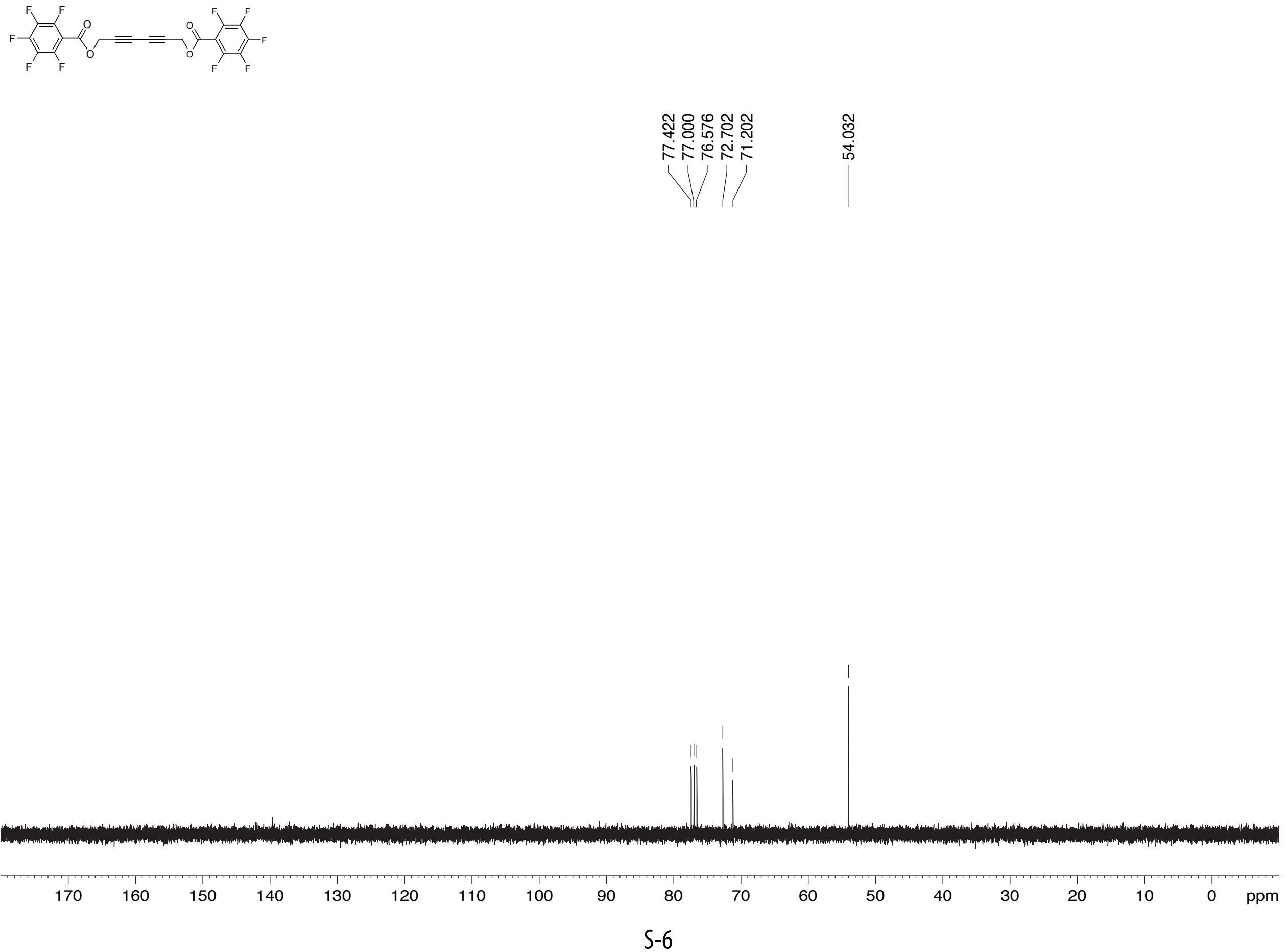
${ }^{19} \mathrm{~F}{ }^{13} \mathrm{C}$ HMQC NMR spectrum of $\mathbf{5}$
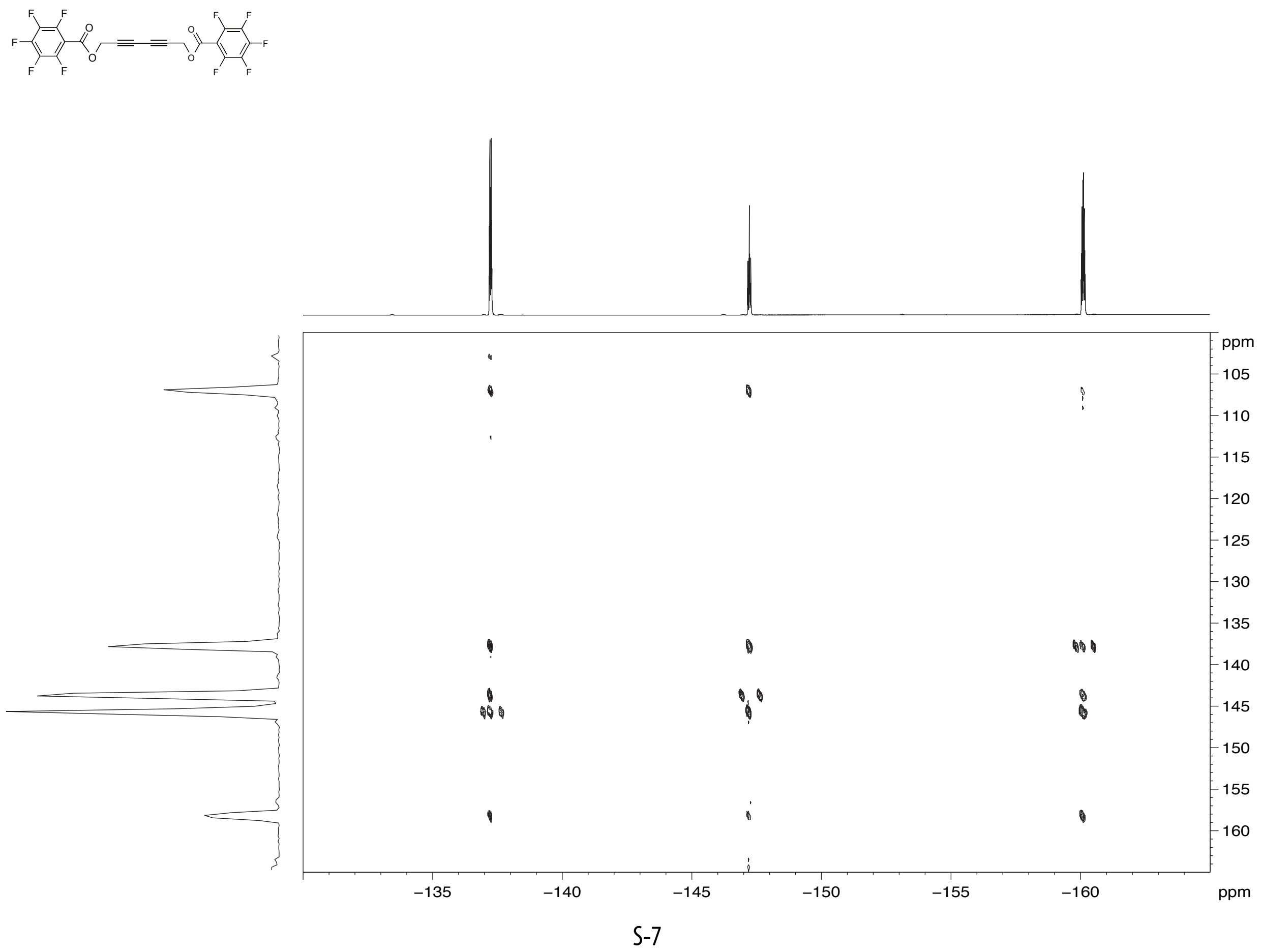


\section{${ }^{1} \mathrm{H}$ NMR spectrum of 6}

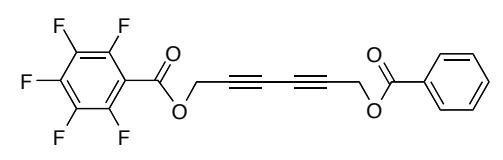

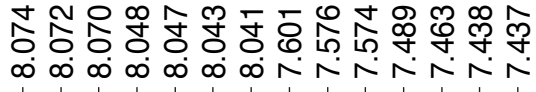

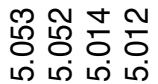

11111

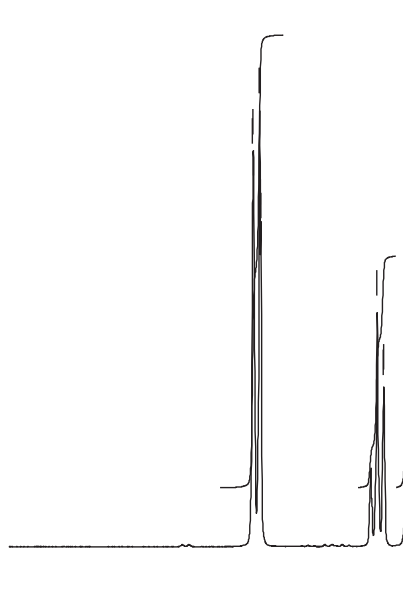

8.5

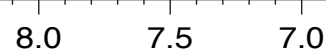

6.5

6.0

5.5

5.0

4.5

4.0

3.5

3.0

2.5

2.0

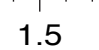

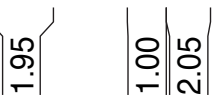

$\left|\begin{array}{c}\stackrel{\sim}{\forall} \\ \dot{\forall}\end{array}\right|$ 


\section{${ }^{13} \mathrm{C}$ NMR spectrum of 6}
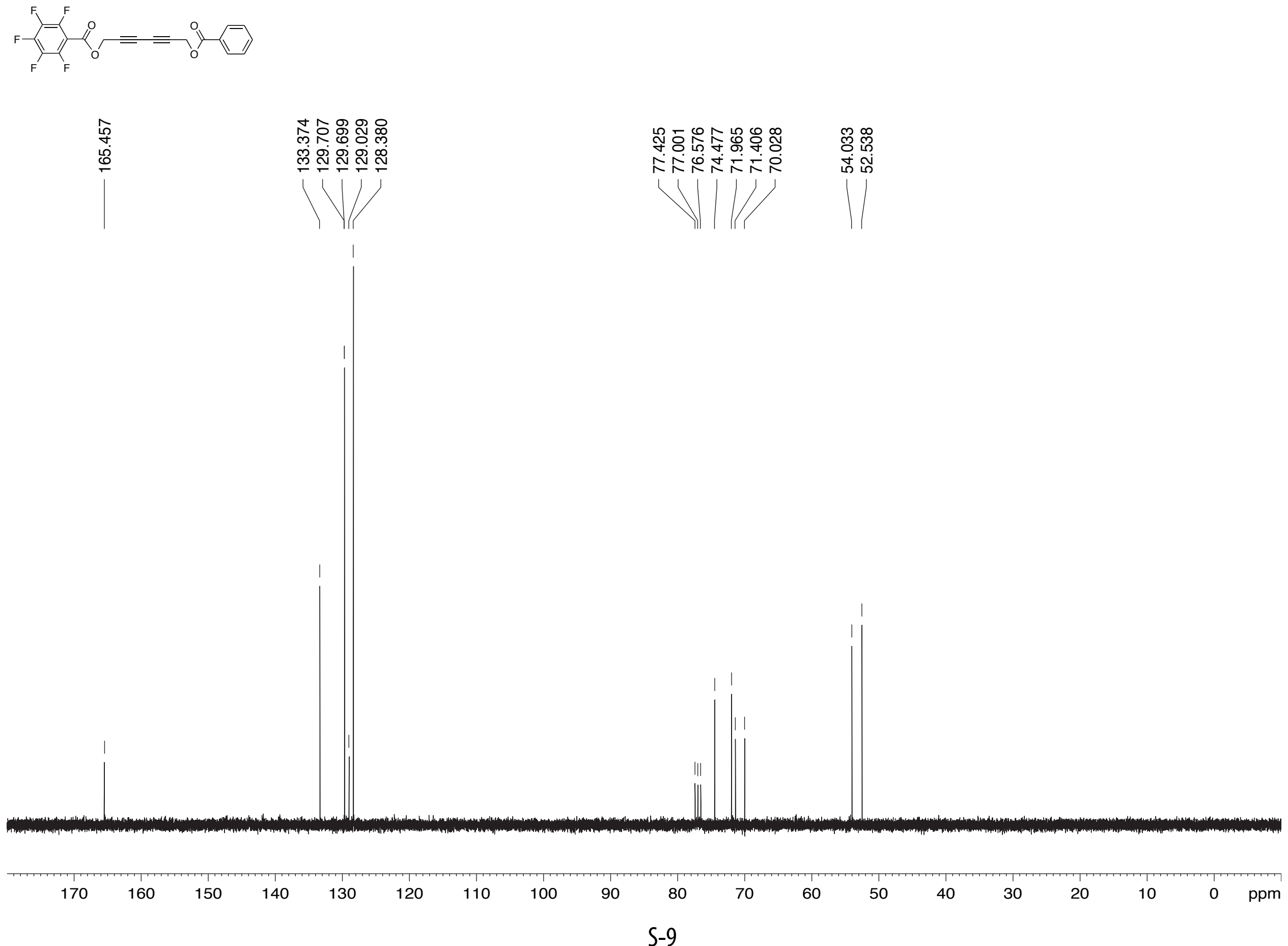
${ }^{19} \mathrm{~F}{ }^{13} \mathrm{C}$ HMQC NMR spectrum of 6
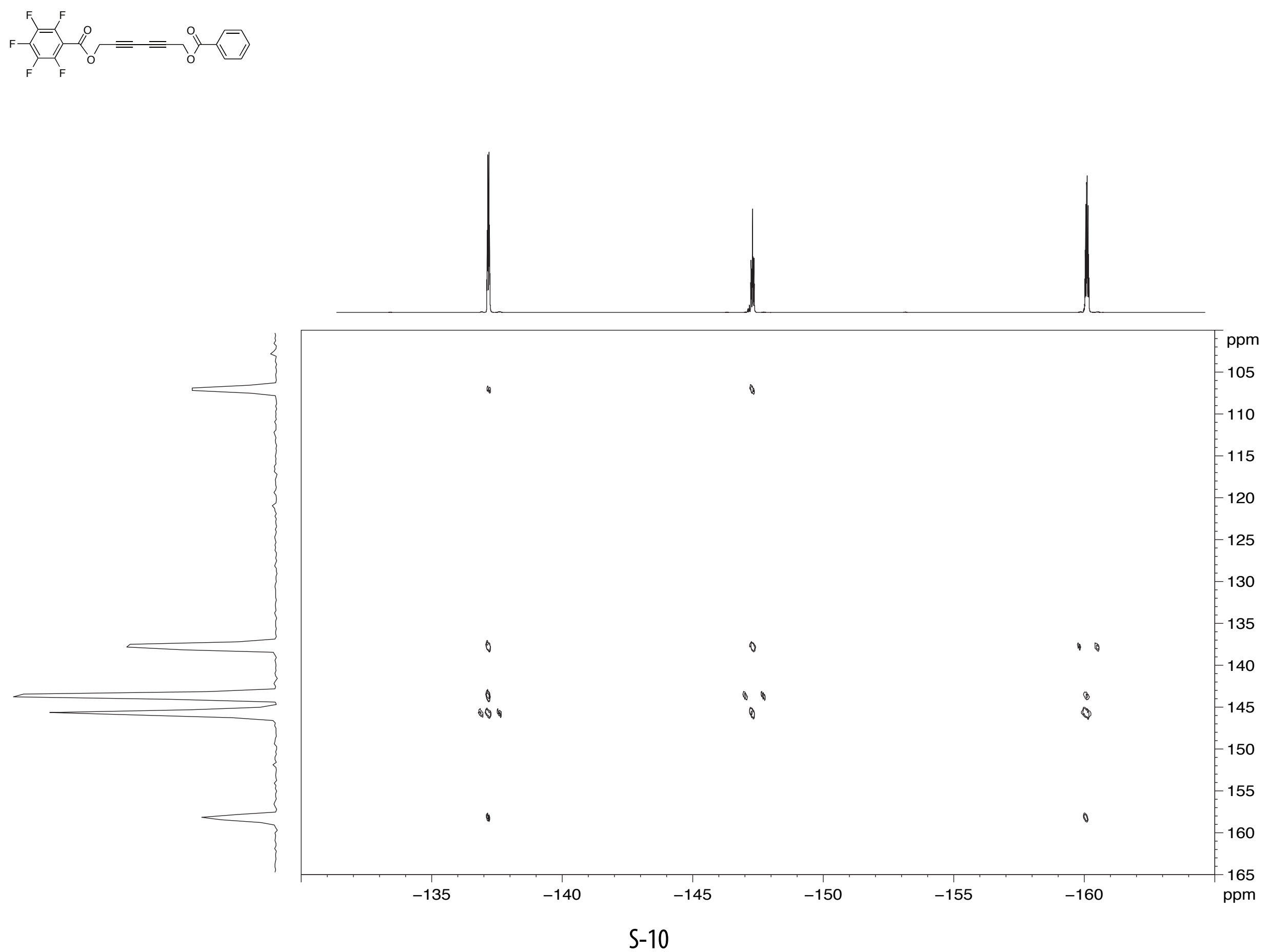


\section{${ }^{1} \mathrm{H}$ NMR spectrum of 8}
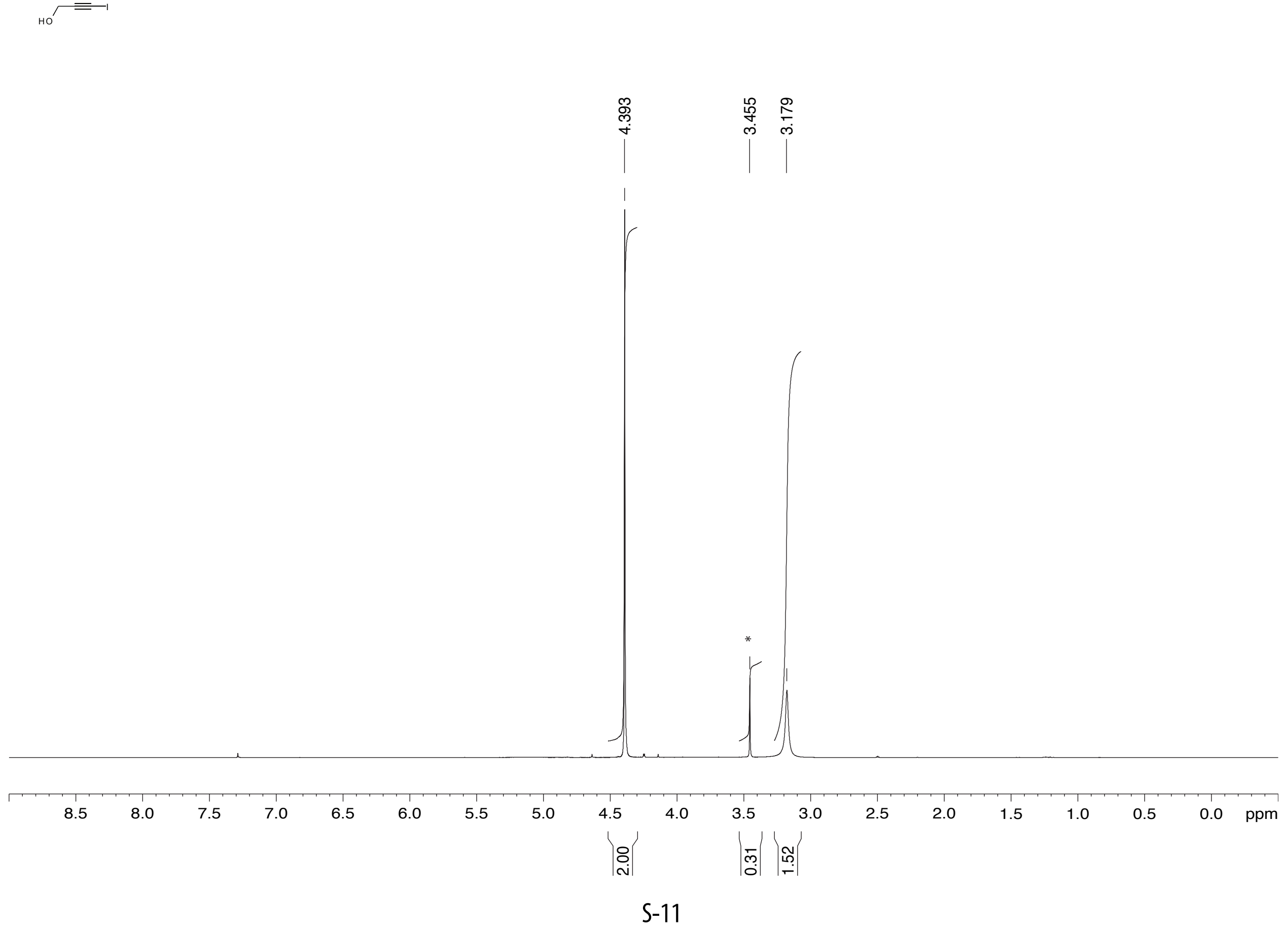
${ }^{13} \mathrm{C}$ NMR spectrum of 8

но $\stackrel{\circ}{=}$

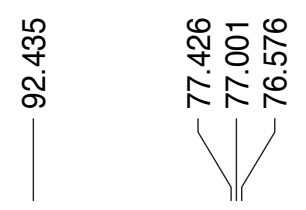

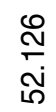

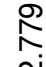

$\mid$

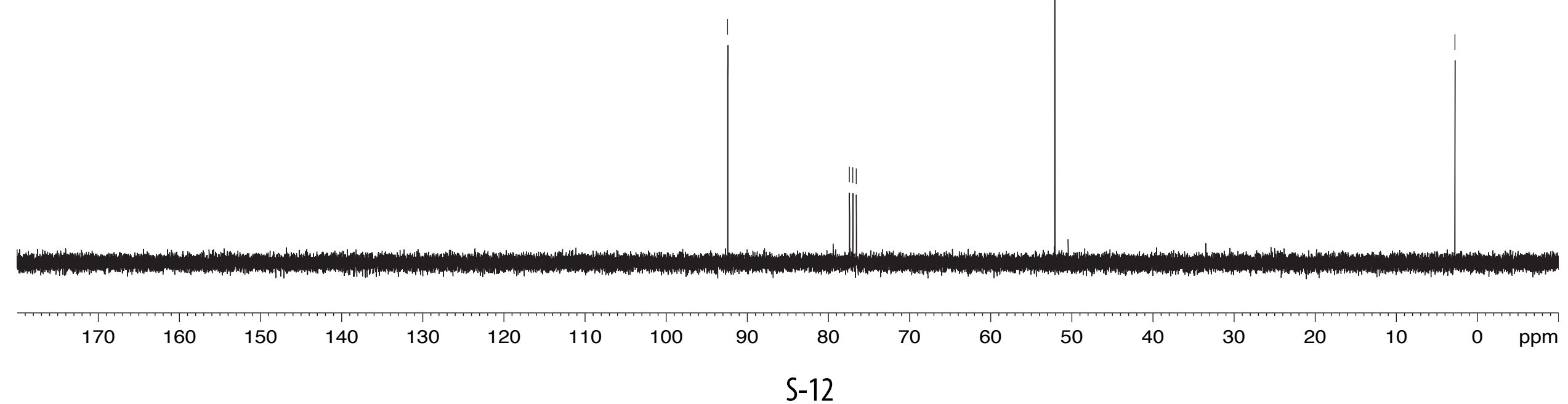




\section{${ }^{1} \mathrm{H}$ NMR spectrum of 9}

$\underset{\substack{Y_{i-0} \\ \lambda}}{ }={ }^{H}$

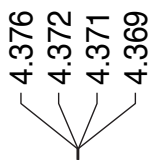

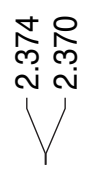

웅 용동뭉

$\ddot{-i}$

1/

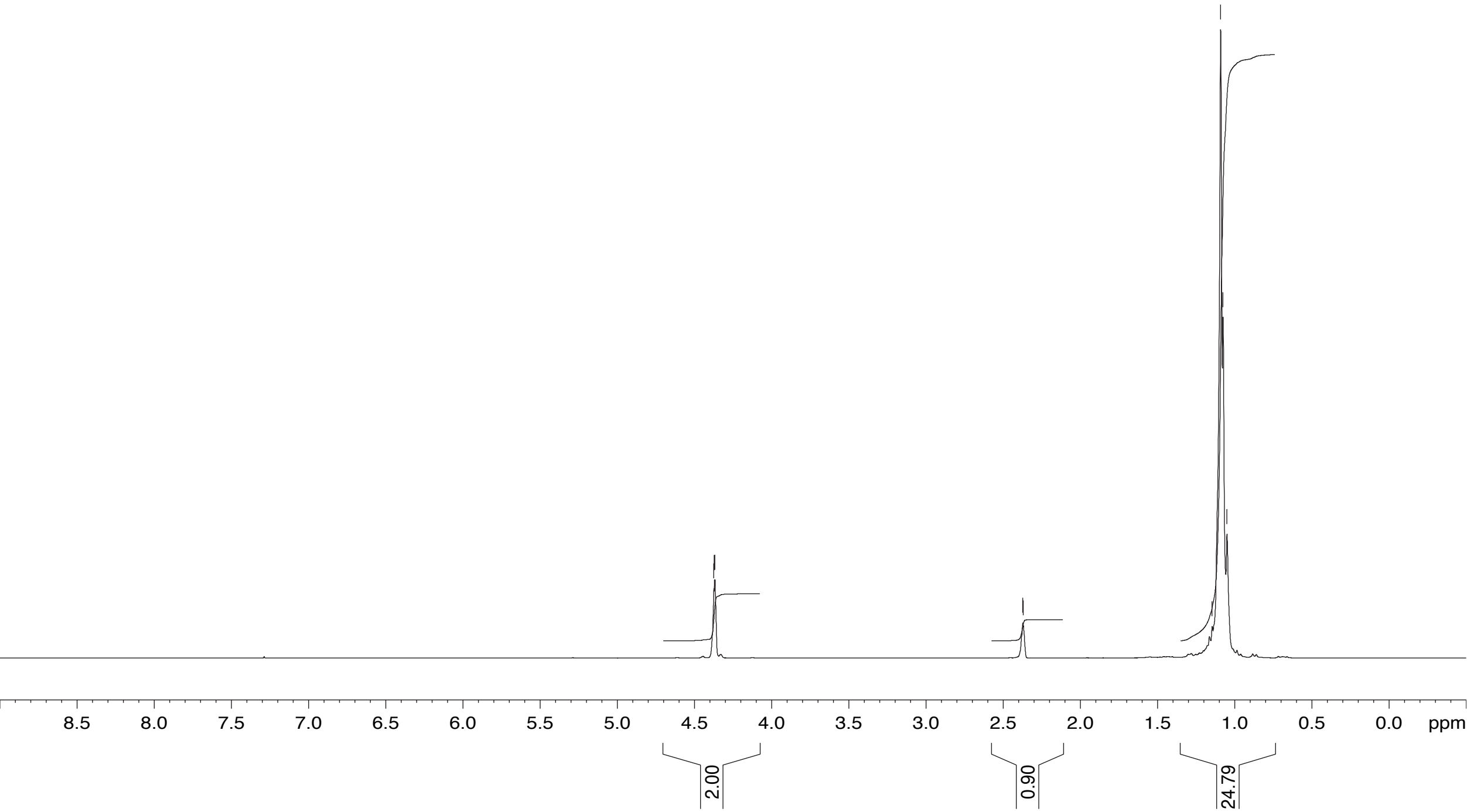

S-13 
${ }^{13} \mathrm{C}$ NMR spectrum of 9

$\underset{\gamma_{\text {si-o }}}{Y}={ }^{-H}$

究

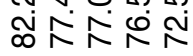

융

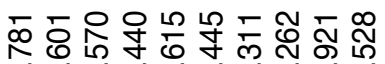

।

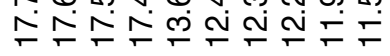

$1 /$

11

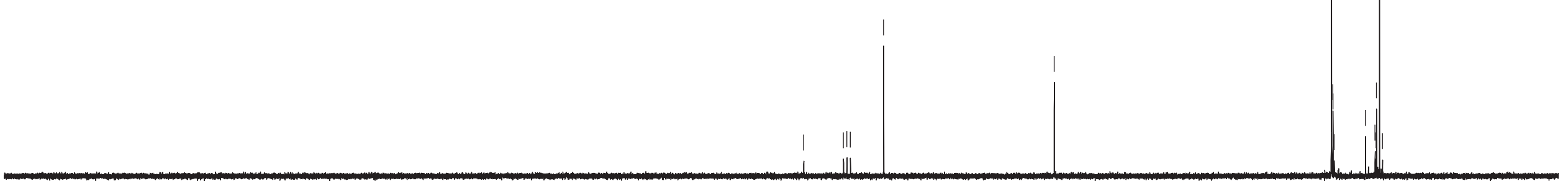




\section{${ }^{1} \mathrm{H}$ NMR spectrum of $\mathbf{1 0}$}

$\underset{\substack{\text { si-o } \\ \lambda}}{Y}={ }_{\text {он }}$

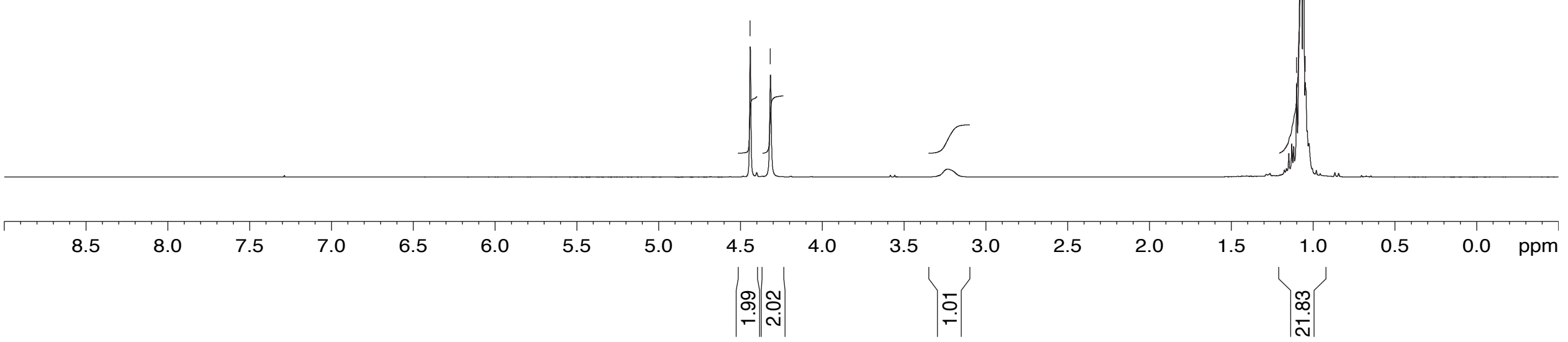




\section{${ }^{13} \mathrm{C}$ NMR spectrum of $\mathbf{1 0}$}

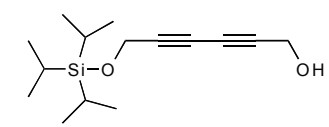

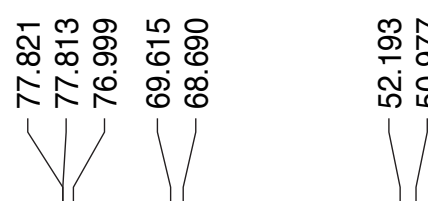

ఫ્م

$\stackrel{+}{\leftarrow} \stackrel{+}{\leftarrow}$

ิํำ

/

广

$\mid$

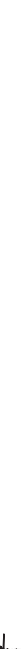




\section{${ }^{1} \mathrm{H}$ NMR spectrum of $\mathbf{1 1}$}

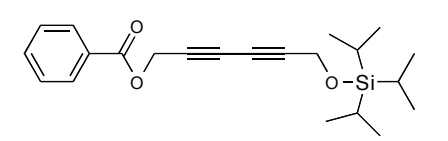

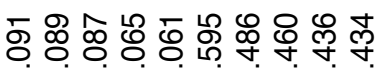

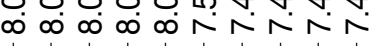

WY $\backslash Y Y$
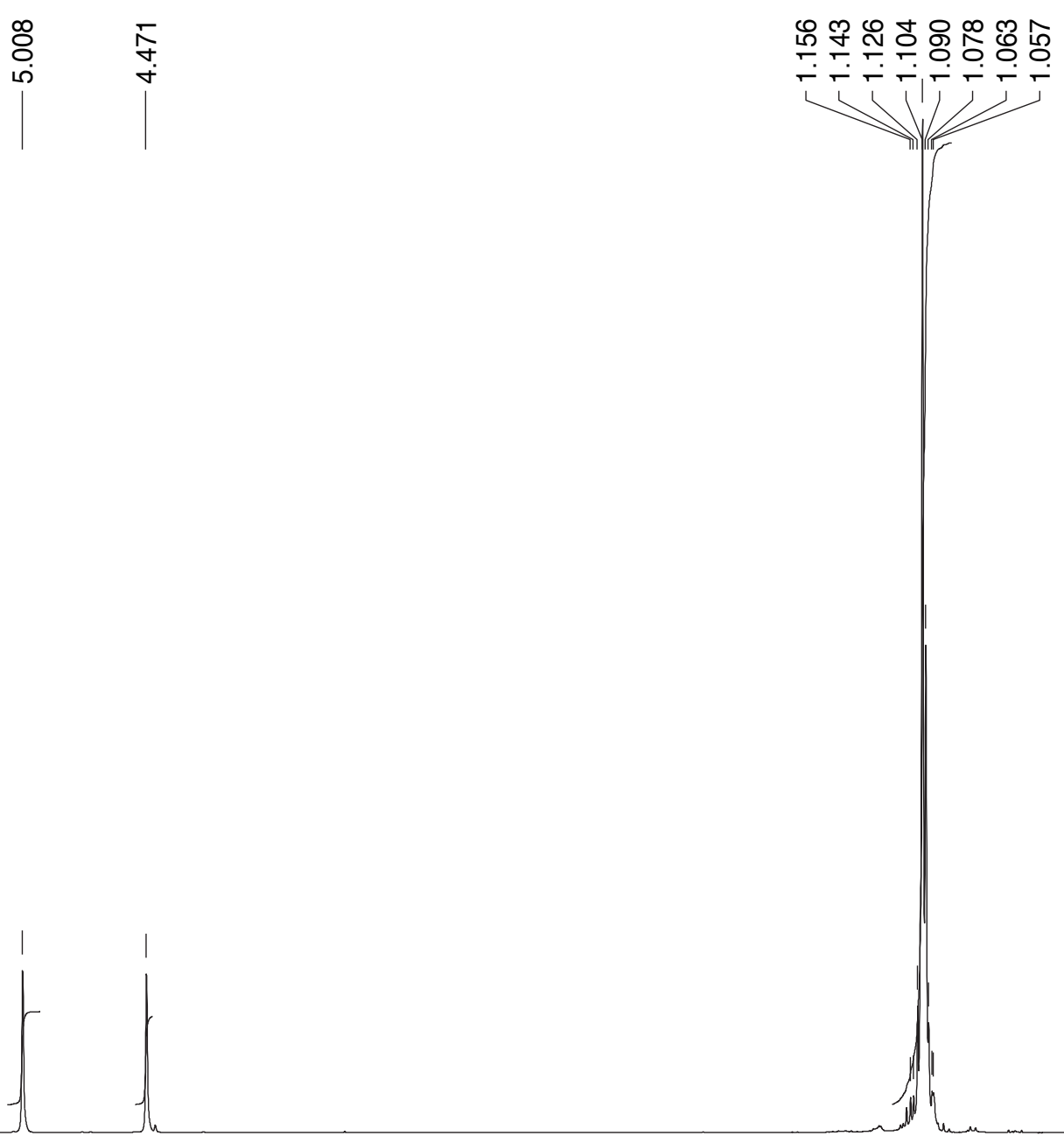


\section{${ }^{13} \mathrm{C}$ NMR spectrum of $\mathbf{1 1}$}
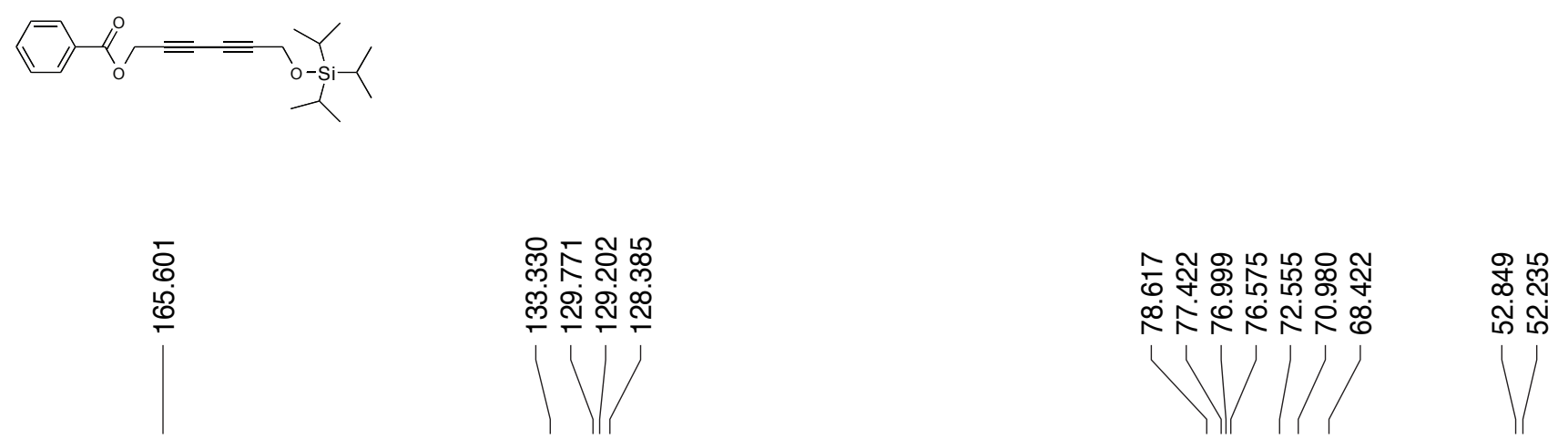

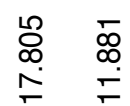

戚这只品

บุำ

V

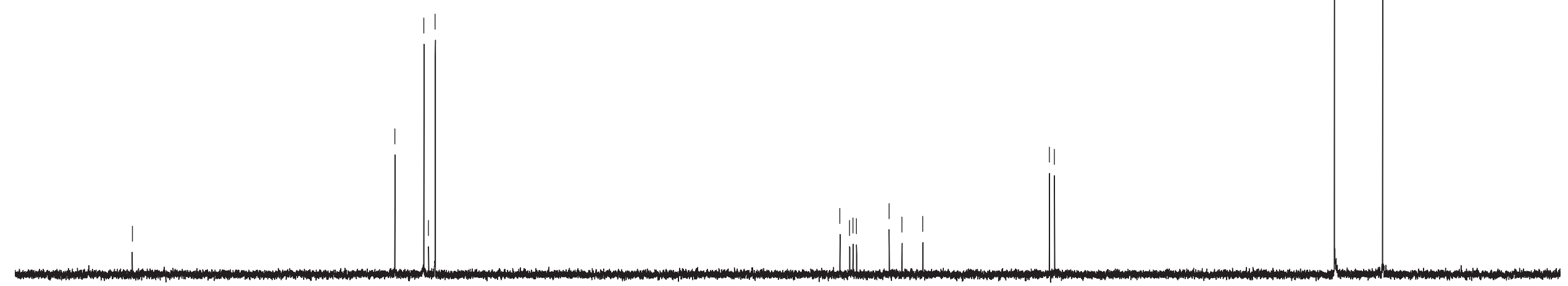




\section{${ }^{1} \mathrm{H}$ NMR spectrum of $\mathbf{1 2}$}

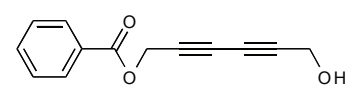

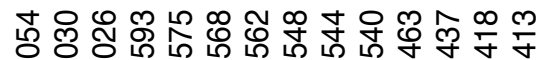
cos os
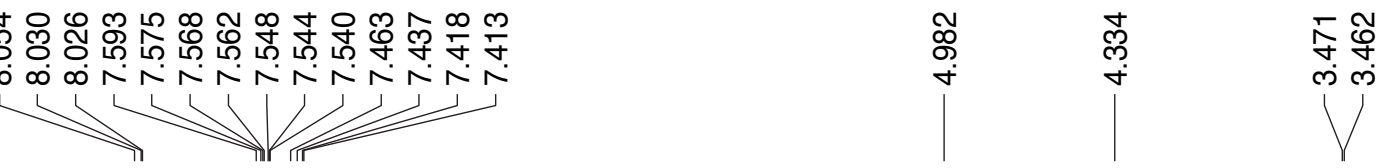

怘 串

mi
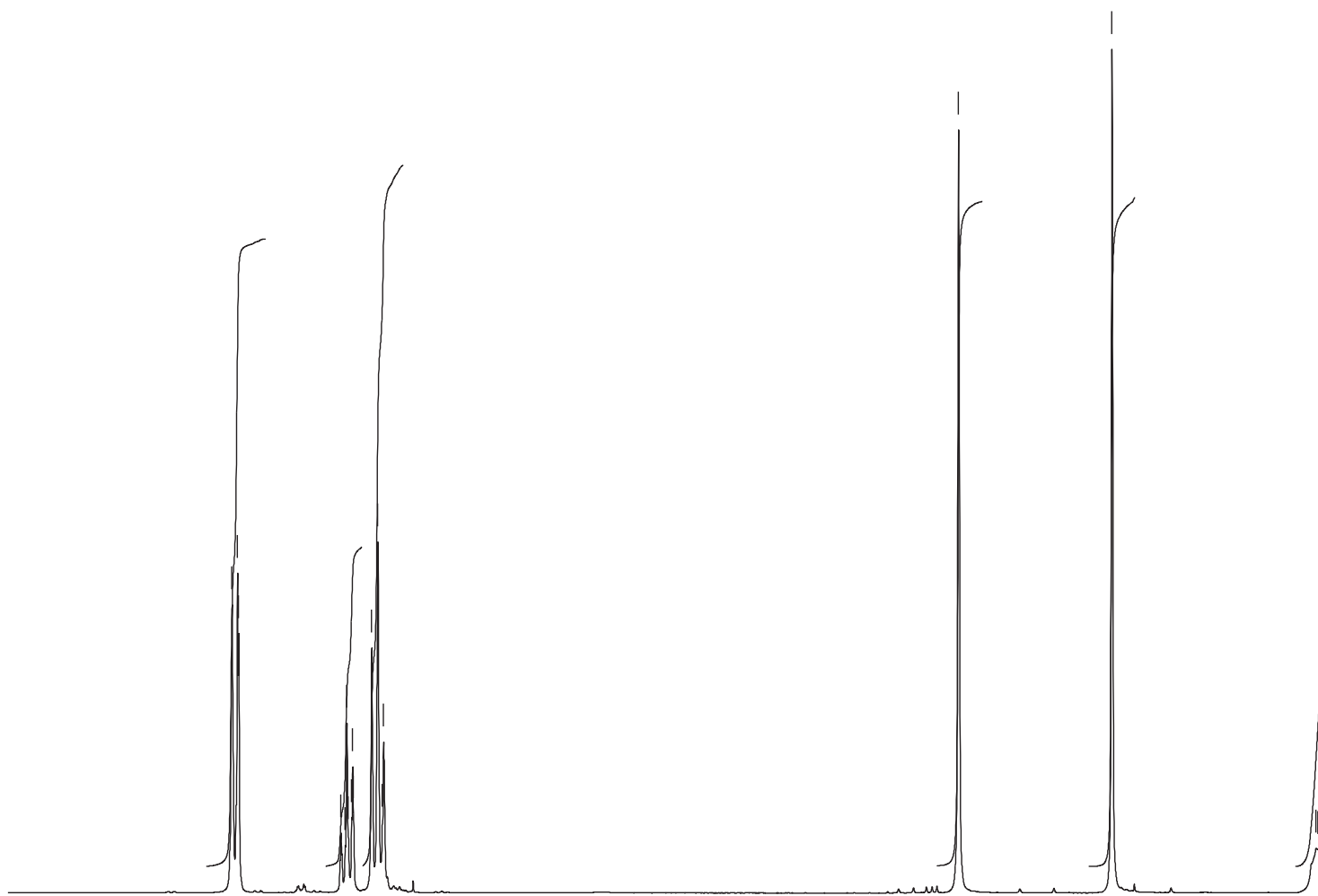


\section{${ }^{13} \mathrm{C}$ NMR spectrum of 12}

$\because \mathrm{O}_{\mathrm{O}}==_{\mathrm{OH}}$

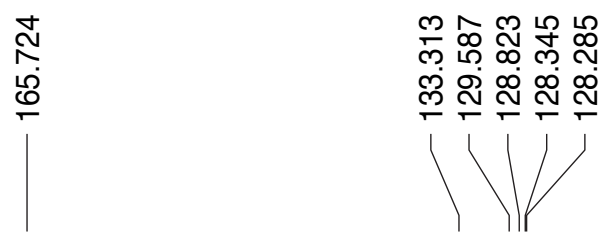

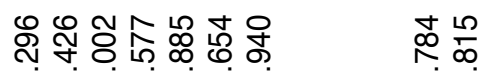

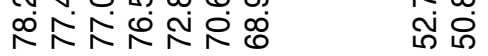

MIII

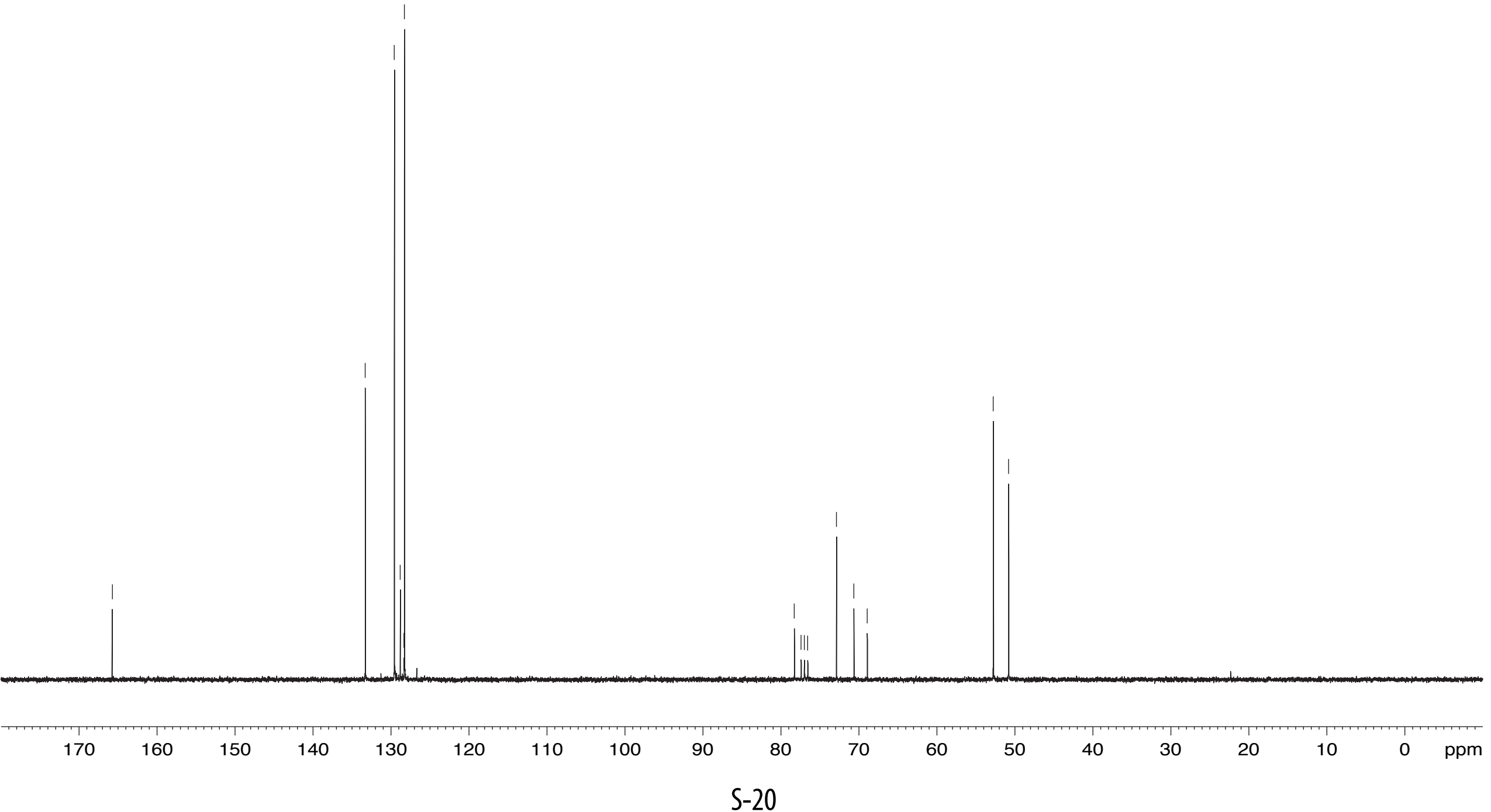




\section{Raman spectrum of $\mathbf{6}$}

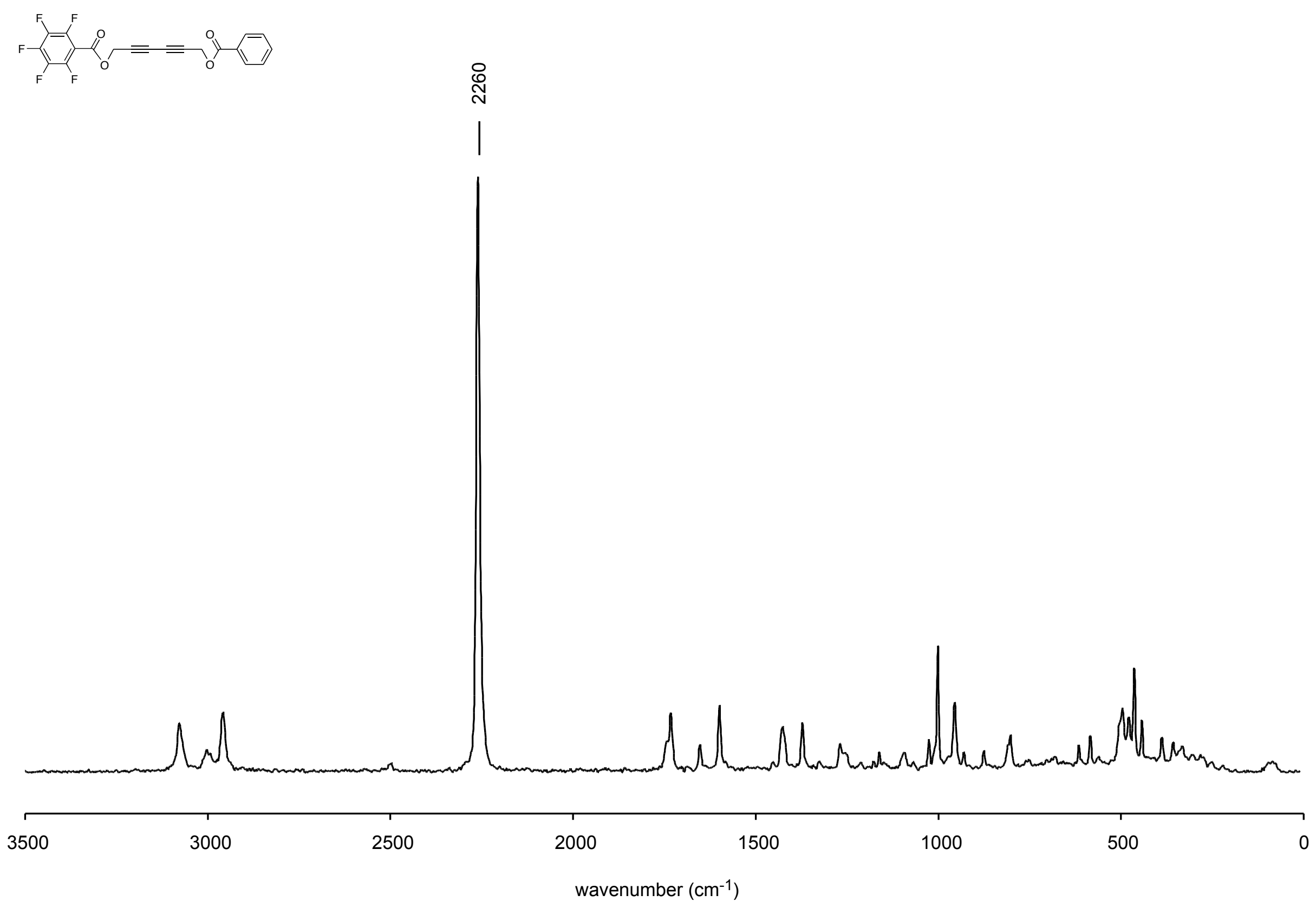


Raman spectrum of the insoluble portion of $\mathbf{6}$ after UV irradiation

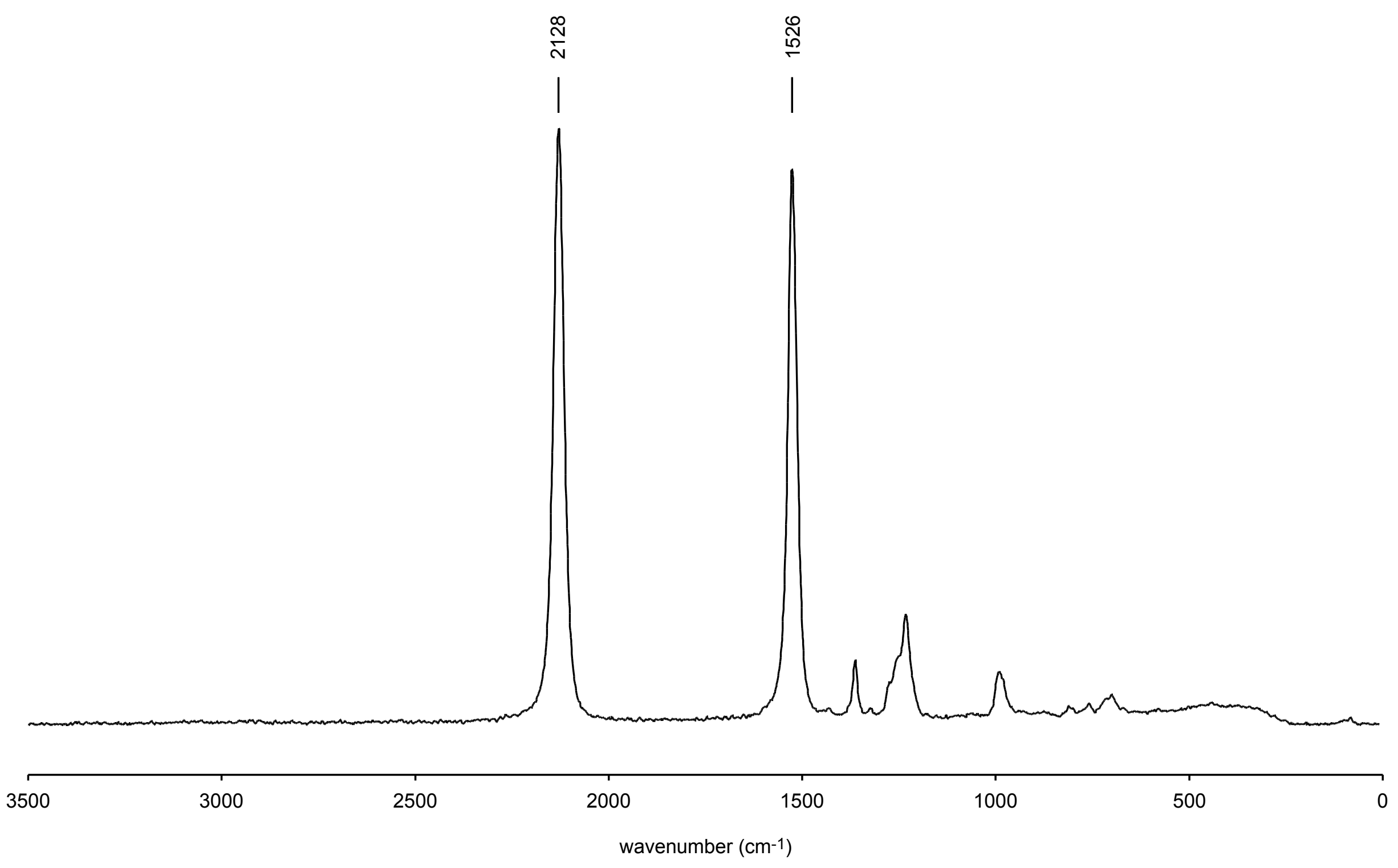




\section{Crystal Structure of $\mathbf{4}$}

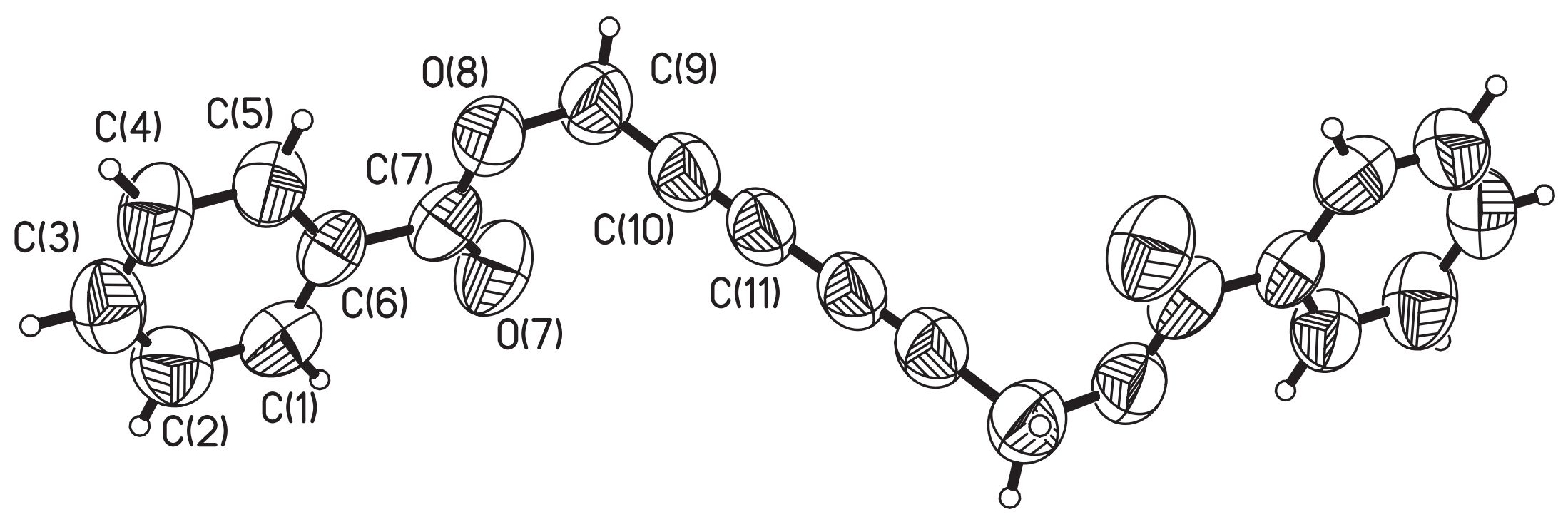


Crystal Structure of $\mathbf{4}$

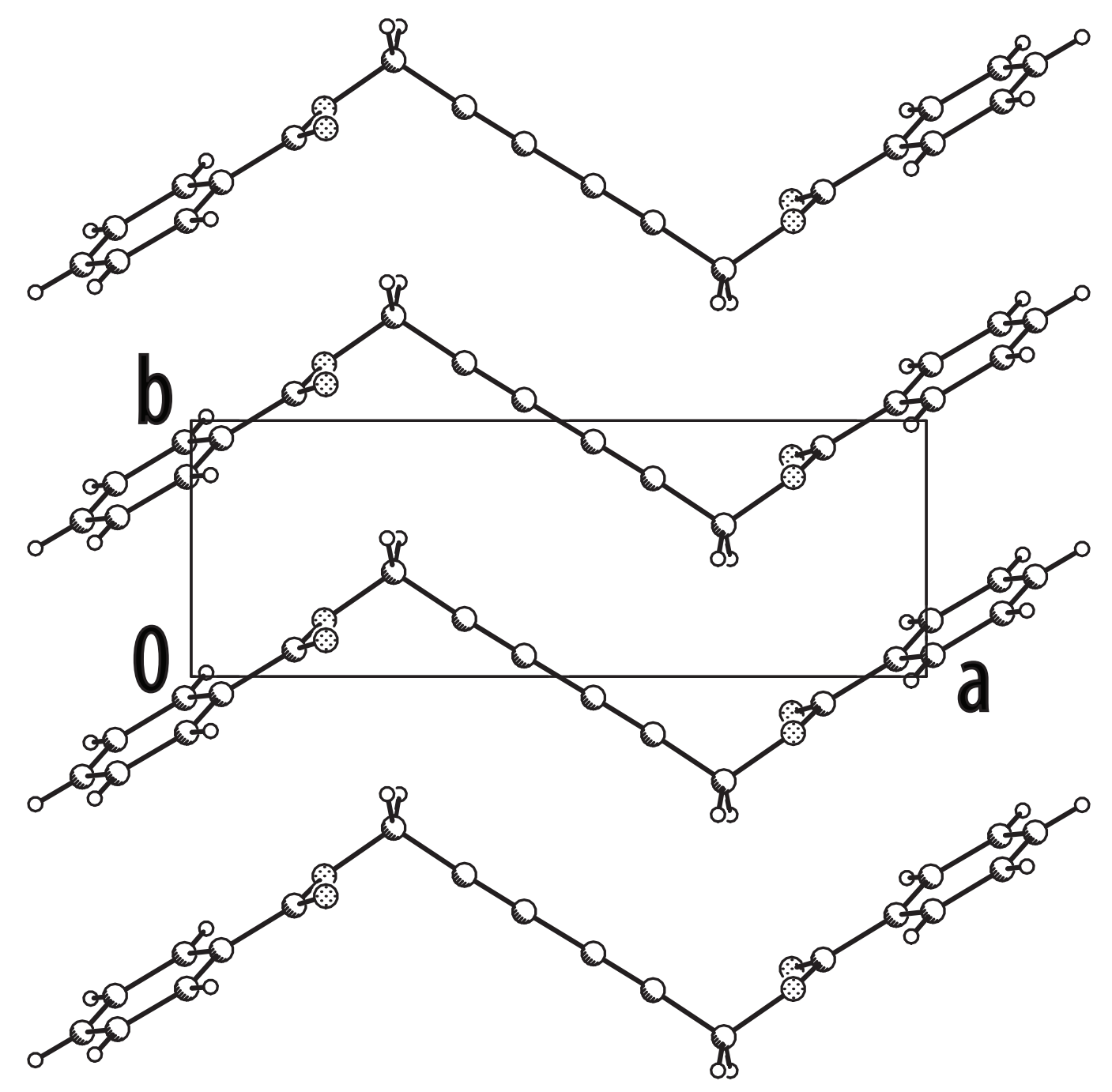




\section{Crystal Structure of $\mathbf{5}$}

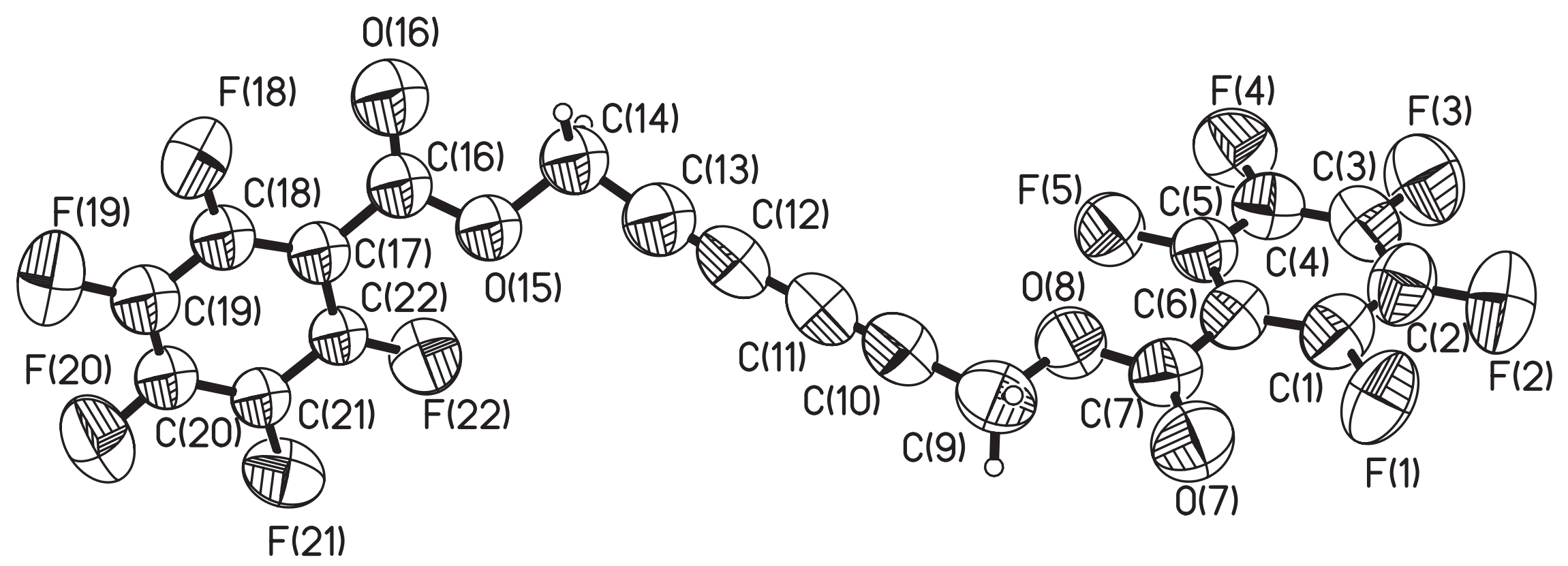


Crystal Structure of $\mathbf{5}$

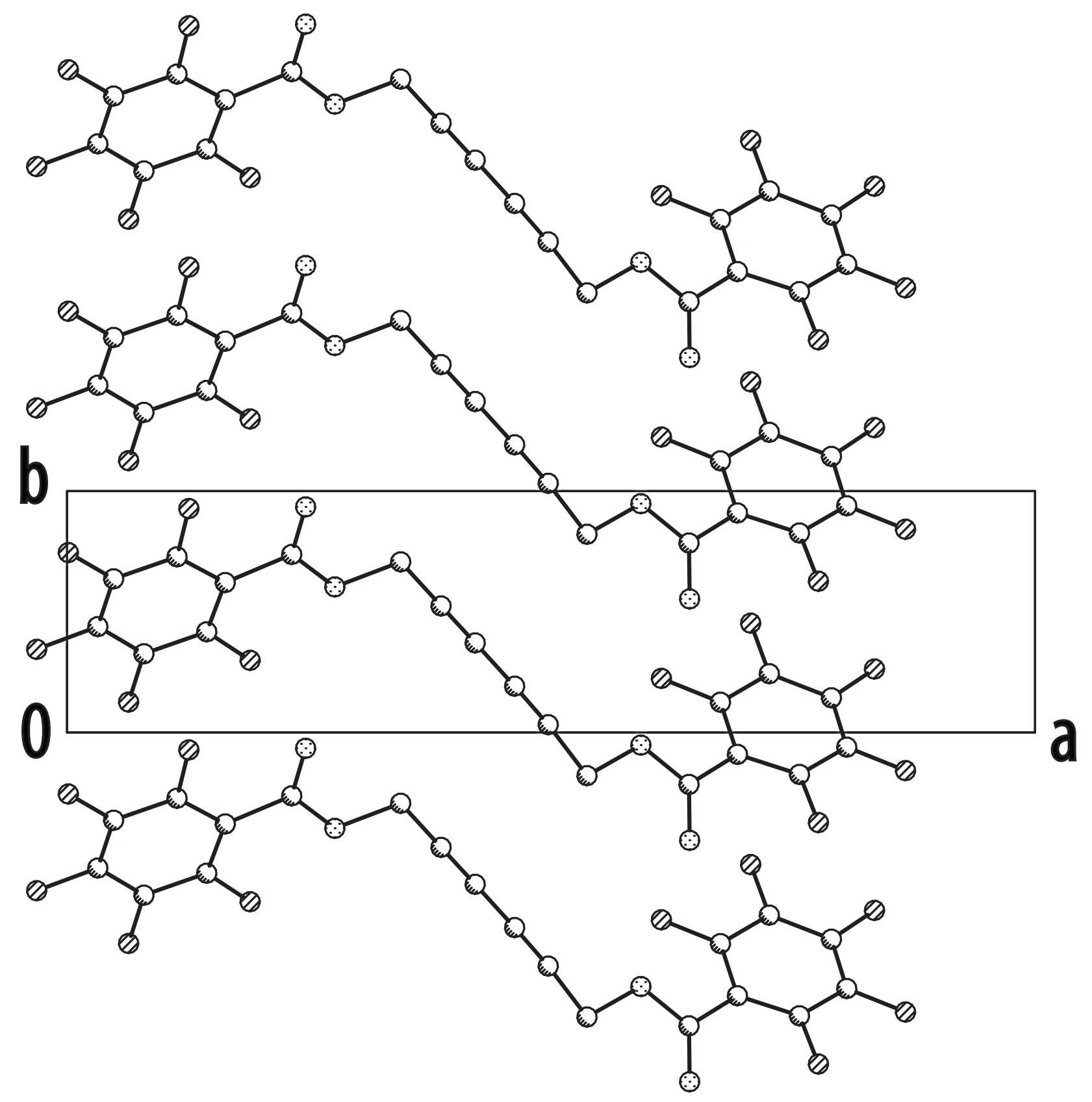




\section{Crystal Structure of 6}

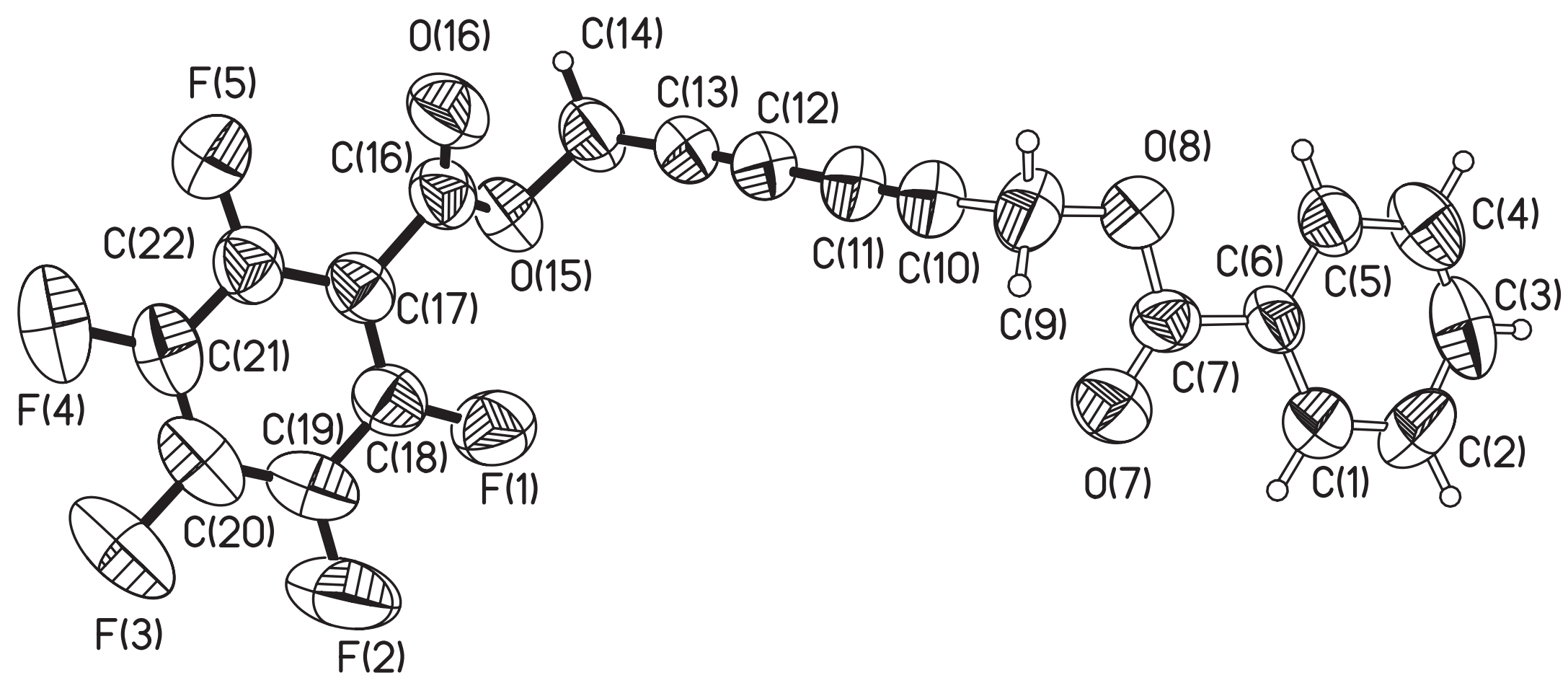


Crystal Structure of $\mathbf{6}$

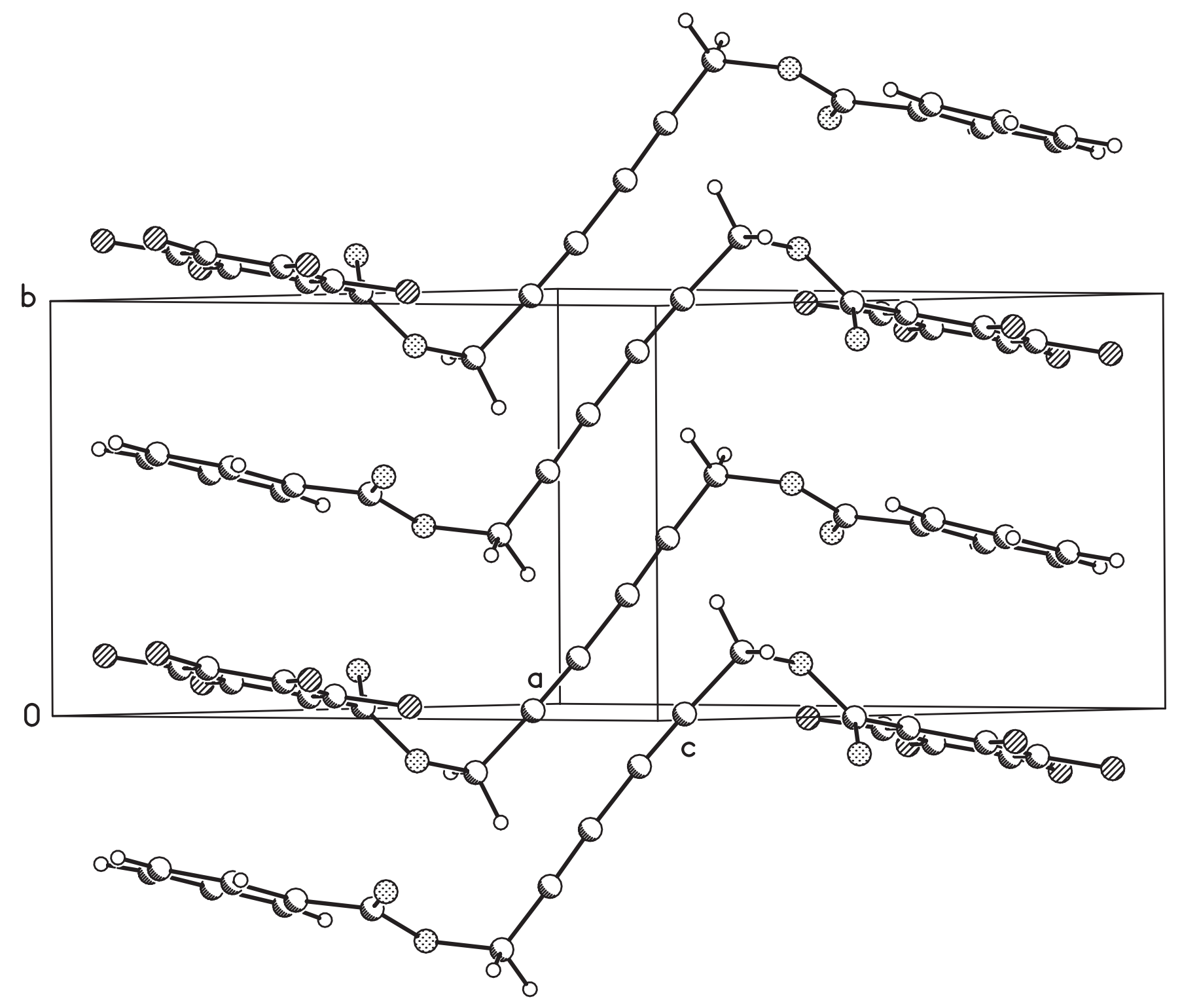

S-28 
Crystal Structure of $\mathbf{4} \cdot \mathbf{5}$
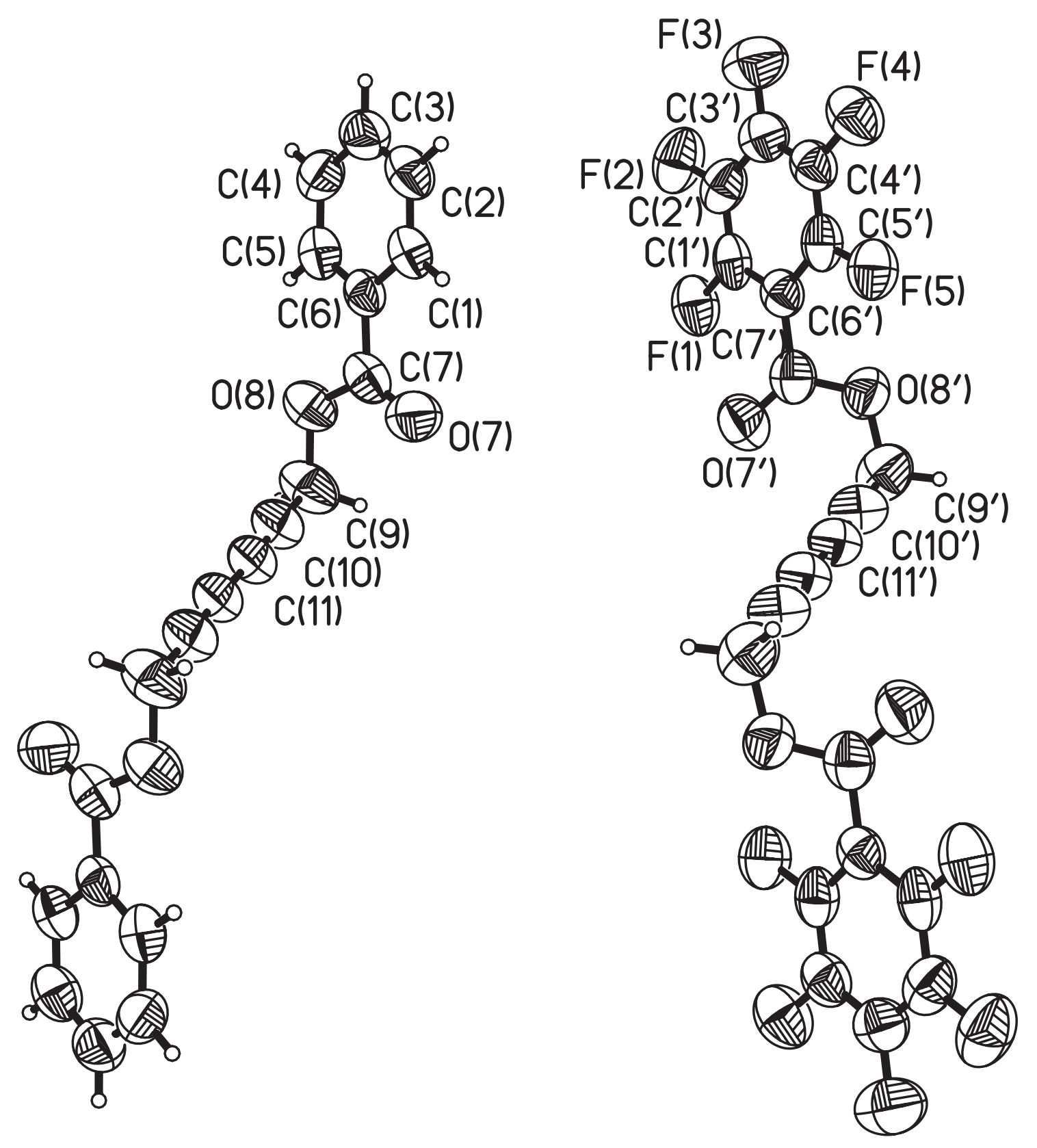
Crystal Structure of $\mathbf{4} \cdot \mathbf{5}$

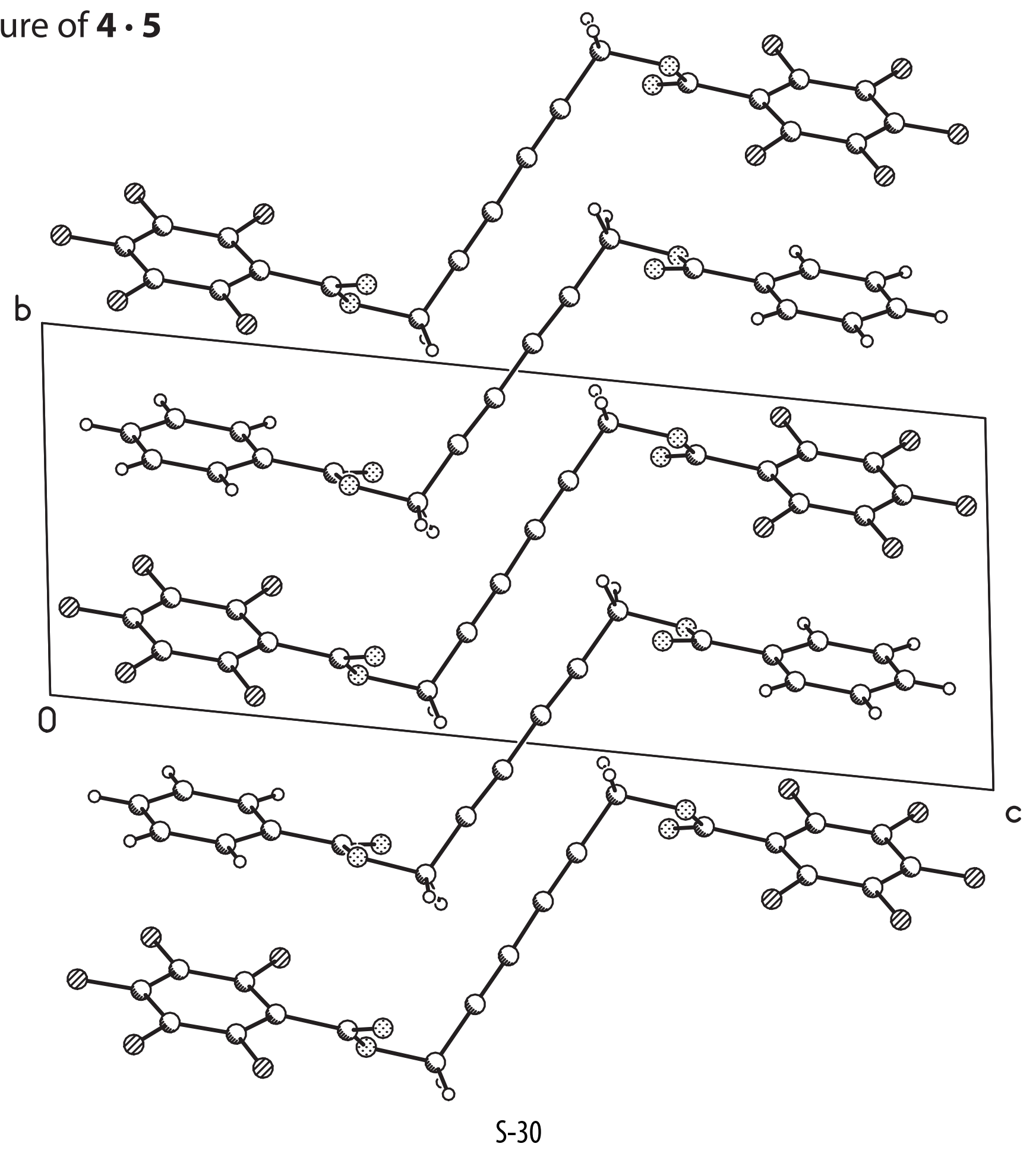


Crystal Structure of $\mathbf{4} \cdot \mathbf{5}$

[1 110$]$

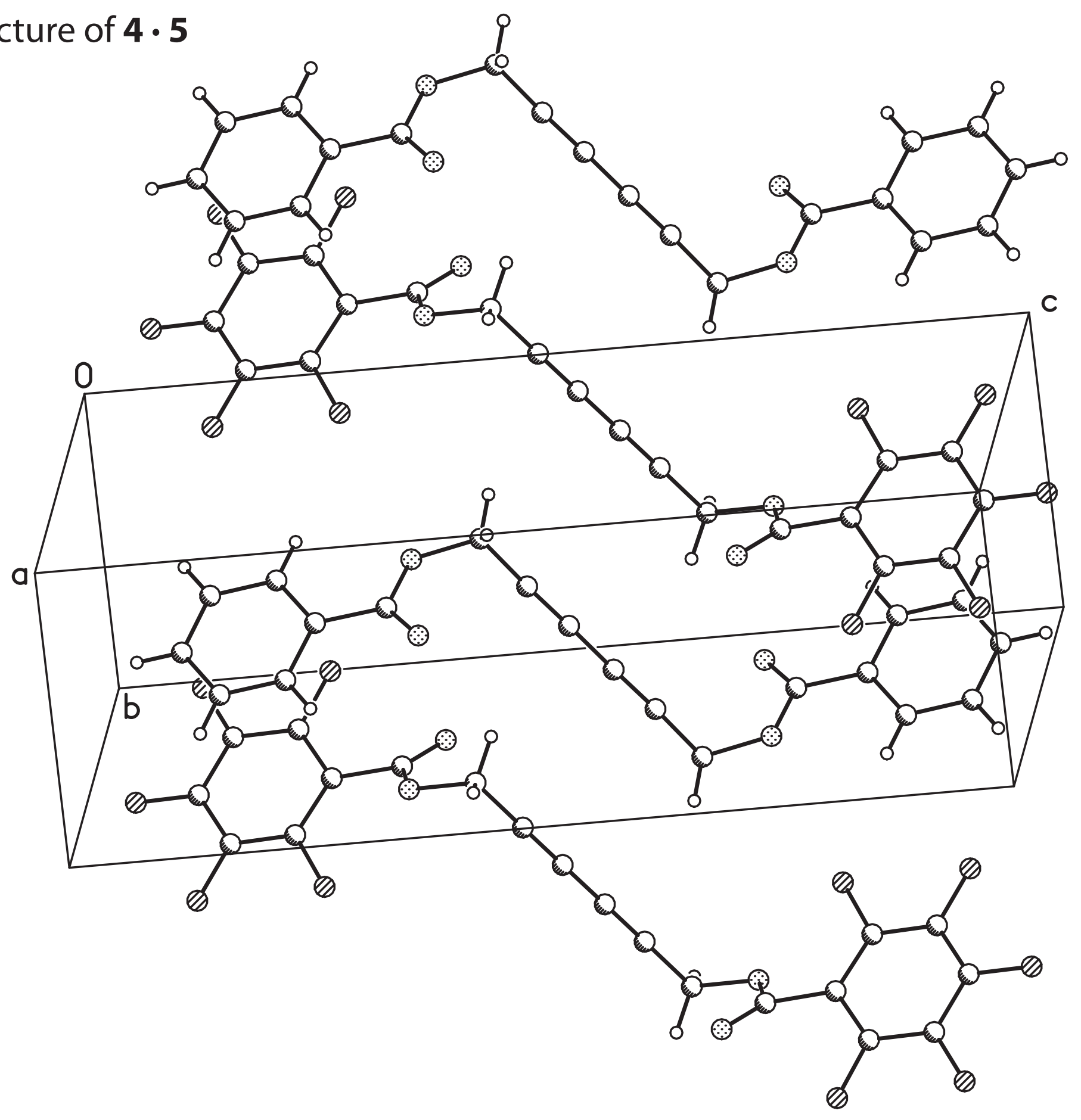

$\uparrow$ 